\title{
Dust storms and their horizontal dust loading in the Sistan region, Iran
}

A. Rashki ${ }^{1,2}$, D.G. Kaskaoutis ${ }^{3}$, C.J.deW. Rautenbach $^{1}$, P.G. Eriksson ${ }^{4}$ M. Qiang ${ }^{5}$, P.

\section{Gupta $^{6}$}

${ }^{1}$ Department of Geography, Geoinformatics and Meteorology, Faculty of Natural and Agricultural Sciences, University of Pretoria, Pretoria 0002, South Africa

${ }^{2}$ Department of Drylands and Desert Management, Faculty of Natural Resources and Environment, Ferdowsi University of Mashhad, Mashhad, Iran

${ }^{3}$ Research and Technology Development Centre, Sharda University, Greater Noida, NCR - 201306, India

${ }^{4}$ Departments of Geology, Faculty of Natural and Agricultural Sciences, University of Pretoria, Pretoria 0002, South Africa

${ }^{5}$ Key Laboratory of Western China's Environmental Systems (Ministry of Education), Lanzhou University 730000 , China

${ }^{6}$ Universities Space Research Association, Greenbelt, MD, USA

*Corresponding author. Tel.: +27-729090950, Fax: +27-(0)12-420 2489,

E-mail: Alireza.Rashki@up.ac.za

\section{Abstract}

The Sistan region in southeast Iran is considered as one of the most active dust source regions in South west Asia. The strong "Levar" winds in summer favor the uplift of large quantities of dust from the Hamoun basin, which is located in the northern part of Sistan. After a dry period at the end of the 1999s, and due to land-use change and desiccation of the Hamoun lakes, the frequency and severity of dust storms have been significantly increased. Within this framework, this study analyses the aerosol characteristics, dust loading and air quality over the Sistan region. The dust loading was measured using dust traps up to four and eight meters height (with a one meter distance between the traps) at two locations near the Hamoun basin during the period August 2009 to July 2010. The results show large quantities of transported dust that strongly dependent on the duration of the dust events, and secondarily, on the wind 
speed and distance from the source region. The grain size distribution of the dusts reveals that the coarser calibers are found at the station nearer to Hamoun, while the large differences in the grain-size distribution found between the two stations indicate significant spatio-temporal variation in dust characteristics. Furthermore, to assess the air quality, Particulate Matter $\left(\mathrm{PM}_{10}\right)$ concentrations were measured over Zabol city during September 2010 to July 2011, and the Air Quality Index (AQI) was obtained. Daily $\mathrm{PM}_{10}$ levels during intense dust storms rise up to $2000 \mu \mathrm{gm}^{-3}$, even reaching to $3094 \mu \mathrm{gm}^{-3}$, while the monthly mean $\mathrm{PM}_{10}$ variation shows extreme values $\left(>500 \mu \mathrm{gm}^{-3}\right)$ for the period June to October. Analysis of the AQI shows that $61 \%$ of the days are associated with a high health risk, while $30.1 \%$ are even identified as hazardous.

Keywords: Dust storm, Levar wind, dust loading, grain size, Sistan region, Iran

\section{Introduction}

Due to the significant impact of dust outbreaks on solar and thermal radiation, aerosols, climate, human health and ecosystems, numerous studies have been conducted worldwide using a variety of instrumentation and techniques to analysis dust storms and their affect on air quality, land use, society and biodiversity (Goudie, 1983; Goudie and Middleton, 1992, 2006; Middleton and Goudie, 2001; Washington et al., 2003; Engelstaedter et al., 2006; Kaskaoutis et al., 2010a and references therein). Dust storms, as a main source of mineral aerosols, frequently occur in the arid and semi-arid regions over the globe, and are regarded as a serious environmental hazard (Prospero et al., 2002). Each year, several billion tons of soildust is entrained into the atmosphere playing a vital role in solar irradiance attenuation, and affects marine environments, atmospheric dynamics and weather (Tegen and Fung, 1994, Tegen et al., 1996; Dunion and Velden, 2004; Prasad et al., 2007; Singh et al., 2008; Patadia et al., 2009). Moreover, several studies demonstrated that the inhalable airborne Particulate Matter (PM) of dust storms has an adverse impact on human health, especially for children and the elderly (e.g. Dockery and Pope, 1996; Nastos et al., 2010).

Desert dust is considered to be one of the major components of tropospheric aerosols over the 
globe (Mishchenko and Geogdzhayev, 2007) with global flux estimations of 1500-2600 Tg. $\mathrm{yr}^{-1}$ (IPCC, 2007). Anthropogenic sources were previously considered as important dust contributors IPCC, 2001), but more recently (IPCC, 2007) were estimated to contribute only $5-7 \%$ of total mineral dust giving major importance to natural sources. The impact of dust aerosols in the Earth's system depends mainly on particle characteristics such as size, shape and mineralogy (Mahowald et al., 2005), which are initially determined by the terrestrial sources from which the soil sediments are entrained and from their chemical composition (Claquin et al., 1998). On the other hand, particle size distributions provide fundamental information for rock characterization and geological process, including sedimentology, stratigraphy, structural geology, pedology and volcanology (e.g. Kandler et al., 2009). Although, during recent years, satellite remote sensing of dust has been increasingly available with promising and reliable results, in-situ measurements for dust aerosol characteristics and dust loading are still considered as absolutely essential. For this reason, several campaigns have been conducted in the arid areas of the globe, mainly focusing over Sahara as the largest and most active dust source region. Although the dust activity and plume exposures from the Sahara to both Atlantic and Mediterranean ocean has been extensively investigated over the years (see the aforementioned reviews), significantly fewer studies have been conducted over the Middle East and south-west Asia.

The main dust source region in the Middle East and south-west Asia is the Arabian Peninsula and the surrounding deserts, which are more active during the period April to July when dust affects atmospheric aerosol loads and their properties over the region (Smirnov et al., 2002; Kim et al., 2011; Maghrabi et al., 2011) as well as over the northern Arabian Sea (Kaskaoutis et al., 2010b; Satheesh et al., 2010). The arid central Iranian Plateau may also be a source of dust aerosols, especially during the summer season when thermal cyclones usually occur. However, there is little emphasis on the strong influence from these dust events, indicating that they are mainly limited to local scales (Bayat et al., 2010). Further to the east, the Thar desert is the main source of dust aerosols affecting northern India and the Himalayas foothills (El-Askary et al., 2006; Hegde et al., 2007; Gautam et al., 2009). Recent studies (Prasad et al., 2009; Gautam et al., 2010) showed that the atmospheric effect of dust emitted from all these regions play an important role in mid-troposphere warming, and therefore the melting of the Himalayan glaciers. Although the Arabian and Thar deserts have been identified as two of the major dust source regions of the globe (Middleton, 1986; Prospero et al., 2002), a small area 
that constitutes a topographically low-lying basin with dried lakes (Hamoun basin) at the borders of Iran, Afghanistan and Pakistan might also play a significant role, but has not yet been studied so far. Very recently, Rashki et al. (2011) reported extremely high $\mathrm{PM}_{10}$

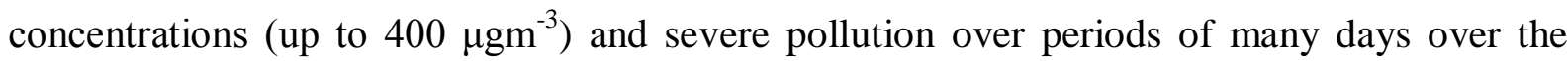
nearby Sistan region, while Alam et al. (2011a) attributed the highest aerosol optical depth (AODs) over Karachi, Pakistan to northwesterly winds and dust storms originated from Hamoun and Sistan (Alam et al., 2011b).

This paper aims at defining the Hamoun basin as a major dust source region by focusing on the assessment of dust loading at two nearby locations. The experimental campaign took place from August 2009 to July 2010, a period where the dust loading at different altitudes during major dust events from the Hamoun basin were measured. The grain size is used to provide useful information regarding the status of Sistan's dust storms, and the associated public health concerns are analyzed at a nearby city (Zabol) by PM measurements. Such studies are currently lacking from this region, and the work in this paper is the very first that examines the evolution of dust sediments over the Sistan arid environment.

\section{Study area}

The Sistan region $\left(30^{\circ} 5^{\prime} \mathrm{N}-31^{\circ} 28^{\prime} \mathrm{N}\right.$ and $\left.61^{\circ} 15^{\prime} \mathrm{E}-61^{\circ} 50^{\prime} \mathrm{E}\right)$ is located close to the Iranian border with Pakistan and Afghanistan, in the southeastern part of Iran (Fig. 1). The region has four cities and 980 villages, with a population of more than 400,000. The climate is arid, with an annual average precipitation of $55 \mathrm{~mm}$ occurring mainly in winter (December to February) while evaporation exceeding 4000 mm.year ${ }^{-1}$ as a result of high temperatures (Moghadamnia et al, 2009). During the summer season, the area is under the influence of a low pressure system attributed to the Indian thermal low that extends further to the west as a consequence of the south Asian monsoon system. The low pressure conditions are regarded as the trigger for the development of the Levar northerly wind, commonly known as the "120-day wind" (Hossenzadeh, 1997), causing frequent dust and sand storms, especially during the summer (June to August) (Goudie and Middleton, 2000; Middleton, 1986) and contributing to the deterioration of the air quality (Rashki et al., 2011). The Hirmand river (also known as the Helmand river) is the longest river in Afghanistan, and is the main watershed for the Sistan 
basin since agricultural crop lands are irrigated from the river. This river finally drains into the natural swamp of the Hamoun lake complex (e.g. Hamoun Saburi, Hamoun Puzak) that is located to the north of the Sistan region (Fig. 1) and is the largest freshwater ecosystem in the Iranian Plateau, and one of the first wetlands identified in the Ramsar Convention (Moghadamnia et al, 2009). Severe droughts over the past decades, especially after 1999, have caused desiccation of the Hamoun lakes, leaving a fine layer of sediment that is easily lifted by the wind and therefore making the basin one of the most active sources of dust in south-west Asia (Middleton, 1986; Goudie and Middleton, 2006). The strong winds, especially during the summer season, blow fine sands off the exposed lake bed and deposit this detritus within huge dune bed forms that may cover a hundred or more villages along the former lakeshore. As a consequence, the wildlife around the lake has been negatively impacted and fisheries have been brought to a halt, which also implies an impact on social society.

\section{Data set and experimental methods}

\subsection{Dust loading measurements and mass quantities}

The amount of dust loadings during dust storms was measured using passive dust samplers (Fig. 2a) fixed at two monitoring towers (four and eight meters above ground level in altitude), with a one meter distance between the two traps (Fig. 2b). Measurements were done over the period August 2009 to July 2010. The towers were erected at two open locations near Hamoun $\left(31.08^{\circ} \mathrm{N}, 61.54^{\circ} \mathrm{E}\right.$ and $\left.31.26^{\circ} \mathrm{N}, 61.76^{\circ} \mathrm{E}\right)$, which are sufficiently distant from any obstacles which ensured that undisturbed wind flow could enter for taking representative dust samples (station A and station B, denoted by red stars in Fig. 1). The dust sampler used in the campaign was developed by the Agricultural and Natural Research Center of Sistan, and is a modified version of the Siphon sand and dust sampler (Ekhtesasi et al., 2006). Although the sampler was originally designed to collect airborne dust, it is also frequently used for soil and sand measurements. At the observation sites, the samplers collect airborne dust sediment. The traps were mounted on a stable parallel to the wind direction. The samplers consist of a tube with a diameter of $12 \mathrm{~cm}$. The sediment-laden air passes through a vertical $2.5 \mathrm{~cm} \times 6 \mathrm{~cm}$ sampler opening in the middle. Inside the sampler, air speed is reduced and the particles settle 
in a collection pan at the bottom, while the air discharges through an outlet with a $U$ shape. After each measurement, the samplers were evacuated to make them ready for measuring the following dust events. The collected samples were oven dried at $105{ }^{\circ} \mathrm{C}$ for 24 hours, and then, dried samples were weighed using an electronic scale with $0.001 \mathrm{~g}$ precision in order to obtain total mass quantities at each sampling height and for each dust storm.

\subsection{Grain-size analysis}

The grain-size distribution of the collected samples was determined with a Malvern Mastersizer 2000 analyzer with a measurement range of 0.02 to $2000 \mu \mathrm{m}$ at Lanzhou University, China. The samples were pretreated with 10 to $20 \mathrm{ml}$ of $30 \% \mathrm{H}_{2} \mathrm{O}_{2}$ to remove organic matter and then with $10 \mathrm{ml}$ of $10 \%$ Hydrochloric acid $(\mathrm{HCl})$ to remove carbonates. About $2000 \mathrm{ml}$ of de-ionized water was added, and the sample solution was kept for about 24 $\mathrm{h}$ to rinse acidic ions. The residue sample was finally treated with $100 \mathrm{ml}$ of $0.05 \mathrm{M}\left(\mathrm{NaPO}_{3}\right)_{6}$ on an ultrasonic vibrator for $10 \mathrm{~min}$ to facilitate dispersion before grain-size analysis. The Mastersizer 2000 automatically yields the median diameter and the percentages of the related size fractions of a sample with a relative error of less than $1 \%$.

\section{3 $\mathrm{PM}_{10}$ measurements}

Supplementary to the dust loading measurements, particles smaller than $10 \mu \mathrm{m}$ in diameter $\left(\mathrm{PM}_{10}\right)$ concentrations have been measured in the city of Zabol in order to provide information about the air quality within the urban environment by using an automatic Met One BAM 1020 beta gauge monitor (Met One, Inc.,) -. The instrument measures $\mathrm{PM}_{10}$ concentrations (in $\mu \mathrm{gm}^{-3}$ ) with a temporal resolution of one hour. The measurements were carried out at the Environmental Institute in Sistan located at the outskirts of Zabol during the period September 2010 to July 2011 (total of 316 days). The recording station is close to the Hamoun basin and stations one and two were placed in the main pathway of the dust storms of the Sistan region. The hourly measured $\mathrm{PM}_{10}$ data were daily averaged, from which the monthly values and variations were obtained. For further assessing the air quality over Zabol, the $\mathrm{PM}_{10}$ concentrations were used to calculate an Air Quality Index (AQI). Based on the 
technological rules related to AQI, the following formula was used to derive the $\mathrm{PM}_{10}$ concentration from AQI (Triantafyllou et al., 2006; Larissi et al., 2010a):

$$
I=\frac{I_{\text {high }}-I_{\text {low }}}{C_{\text {high }}-C_{\text {low }}}\left(C-C_{\text {low }}\right)+I_{\text {low }}
$$

Where $\mathrm{I}$ is the concentration of $\mathrm{PM}_{10}, \mathrm{I}_{\text {low }}$ and $\mathrm{I}_{\text {high }}$ are AQI grading limited values that are lower and larger than I (AQI index), respectively, and $\mathrm{C}_{\text {high }}$ and $\mathrm{C}_{\text {low }}$ denote the $\mathrm{PM}_{10}$ concentrations corresponding to $\mathrm{I}_{\text {high }}$ and $\mathrm{I}_{\text {low }}$, respectively.

\subsection{Ozone Monitoring Instrument aerosol index}

For assessing the aerosol field over the region, the Aerosol Index (AI) values obtained from the Ozone Monitoring Instrument (OMI) that is on board the NASA A-Train Aura satellite were used on monthly basis over the area bounded from $20-34^{\circ} \mathrm{N}$ and $52-72^{\circ} \mathrm{E}$. The AI concern data via the Aura-OMI Level-2G ((OMTO3) with a spatial resolution of $0.25^{\circ} \times 0.25^{\circ}$ were obtained from Giovanni (http://disc.sci.gsfc.nasa.gov/giovanni). Due to its strong reflection in the imaginary part of the refractive index in the Ultra Violet (UV) spectrum (De Graaf et al., 2005), desert dust provides a clear signal of AI values. The main disadvantage is the sensitivity of AI to dust-aerosol layer height, while any aerosol below $\sim 1000 \mathrm{~m}$ above the surface is unlikely to be detected (Hsu et al., 1999). Also, the uncertainties in AI are larger over the swath overlap areas (see Kaskaoutis et al., 2010c), but these areas have been automatically excluded from the analysis. Recently OMI instrument has gone through row anomalies, therefore quantitative use of the data has been avoided in the study (see http://disc.sci.gsfc.nasa.gov/Aura/data-holdings/OMI/index.shtml\#info).

\section{Results and discussion}

\subsection{Meteorology and climatology of Sistan}

Before analyzing the aerosol field over the study region, some useful information of the meteorology and climatology as obtained from the Zabol meteorological station 
(http://www.irimo.ir/english/current/index.asp?station=40829) are provided. Fig. 3 presents the annual variation of mean Temperature (T), Relative Humidity (RH) and atmospheric Pressure (P) over Zabol over the period 1963 to 2010. The monthly mean T exhibits a clear annual pattern with low values in the winter $\left(9\right.$ to12 $\left.{ }^{\circ} \mathrm{C}\right)$ and high $\left(\sim 35^{\circ} \mathrm{C}\right)$ in summer, following the common pattern found in the northern Mid-latitudes. During the summer period the maximum $\mathrm{T}$ often goes up to 46 or $48{ }^{\circ} \mathrm{C}$ causing an extremely large diurnal variation which is a characteristic of many arid environments. RH illustrates an inverse annual variation with larger values in winter (50 to $57 \%$ ) and very low values in summer ( $25 \%)$, which are about 10 to $15 \%$ during daytime. During the period October to April P values are generally high in winter (1020 to $1024 \mathrm{hPa}$ ), which is above the standard mean sea level value of 1013.25 hPa. P values decrease during summer ( $996 \mathrm{hPa}$ in July). The latter is a consequence of the Indian thermal low that develops over the entire south Asia during summer monsoon months. This has a direct impact on the intensity of the winds over the region, which has a monthly mean of as high as $12 \mathrm{~m} \cdot \mathrm{s}^{-1}$ during June and July (Fig. 4) with frequent gusts of above 20 to $25 \mathrm{~m} . \mathrm{s}^{-1}$. In contrast, during late autumn and winter months the wind speed is confined to $\sim 3$ to $4 \mathrm{~m}^{-1} \mathrm{~s}^{-1}$. The annual variation of visibility follows an inverse pattern, with large values in winter, usually above $10 \mathrm{~km}$, and very low in summer $(<4 \mathrm{~km}$ on average). A power-decreasing curve relation associated with $93 \%$ of the variance is observed between wind speed and visibility. This inverse relation indicates that the wind speed does not act as a ventilation phenomenon over Zabol, as usually occurs in coastal urban environments with local sea-breeze cells (Adamopoulos et al., 2007), but rather as a factor responsible for the deterioration of visibility, since the intense Levar winds are the genesis cause for the dust outbreaks over Sistan.

Although the visibility exhibits a clear annual pattern (Fig. 4), long-term data series over Zabol shows that it contains considerable year-to-year variations (Fig. 5a). Focusing on recent years, the days with visibility $<=2 \mathrm{~km}$ have been dramatically increased from about 20 during 1995 to 1999 to $>100$ during 2000 to 2001 . This is attributed to a severe drought period that dried the largest part of the Hamoun wetlands and favored alluvial uplift, as well as the frequency and mass intensity of dust storms that affected the visibility over Sistan. However, in the 2000s the days with very low visibility seem to have a decreasing trend, but remaining above the standards of the climatological mean. Fig. 5b shows the flow chart of wind speed and direction over Zabol during the period 1963 to 2009, and also provides the percentages 
for six wind-speed categories. In all seasons, the northwestern flow clearly dominates, although more apparent in summer, while high percentages for intense winds are also associated with a northwesterly flow. The probability for intense winds to blow from other directions is low. As shown in Fig. 4, summer winds are much more intense with $~ 27 \%$ of wind speeds above $11.1 \mathrm{~m} . \mathrm{s}^{-1}$, while calm conditions are limited to $2.9 \%$ against $18.8 \%$ and $19.6 \%$ for autumn and winter, respectively. The higher frequency and intensity of northwestern winds is the reason for the frequent dust storms that affect Zabol. Zabol is located at the downwind direction of dust storms that normally originate from Hamoun (Fig. 1). Fig. 1 (left panel) shows a severe dust storm over Sistan region as observed from the Terra-MODIS satellite's true color image on 15 June 2004. The intense dust plumes form a giant U shape that extends from Sistan into southern Afghanistan and southwestern Pakistan, and obscures the surface over much of the region. The pale color of this dust plume is consistent with that of dried wetland soils. Furthermore, except of their intensity, the duration of dust storms over Zabol exhibit a clear annual pattern with a higher duration in June - about 50 hours on average (Fig. 6). During the period October to April dust storms are characterized by low frequency and duration, below 5 hours, although in some cases they might still be intense.

\subsection{Aerosol field over the region}

The use of TOMS and OMI AI satellite data presents some promising results for the identification of dust source regions, although they have a larger spatial resolution compared to the MODIS satellite (Baddock et al., 2009). Therefore, the use of OMI-AI satellite data for the identification of major dust sources over south-west Asia will enable us to focus on critical regions and to characterize emission rates in response to environmental conditions. The spatial distribution of the monthly mean AI values for the period August 2009 to July 2010 over the study region is shown in Fig. 7. The spatial distribution of AI values reveals a considerable seasonal variation in aerosol load, in general, and in dust occurrence, in particular. During the winter season (December to February) the AI is generally low, except for some hotspot regions with values of above 1.5, e.g. Hamoun. From March onwards high AI values start to spread over a wider area, covering southern Afghanistan (near to Hamoun), as well as the Arabian and Thar deserts. From here AI values continuously increase until May, 
with the highest increase over the Thar desert influencing the aerosol load in northern India (Gautam et al., 2009; Dey and di Girolamo, 2010). During the monsoon period (June to August) the AI significantly increases over northern Arabian Sea due to the large influence of dust coming from Arabia as well as from Iran and Pakistan due to strong northern Levar winds. This is also the period with the highest AI over Sistan which is closely associated with a reduction in visibility and stronger winds (Fig. 4). From September to November the high AI is limited over Sistan, as well as over some hotspots in Arabia and Pakistan. From the AI spatial distribution one may put emphasis on the large regional differences between Zabol (near to Hamoun basin) and the city of Zahedan, located about $200 \mathrm{~km}$ south. The AI at Zabol is significantly higher during all months, suggesting a larger presence of dust compared to the adjacent southern areas. This is consistent with the large differences in $\mathrm{PM}_{10}$ concentrations found between Zabol and Zahedan (section 4.5).

In synopsis, the spatial distribution of AI during a whole year identified the Hamoun basin as one of the most active dust source regions in South west Asia. In general, the dust sources, regardless of size or wind strength, are usually associated with topographic lows in close proximity to mountains and highlands with annual rainfall of less than 200 to $250 \mathrm{~mm}$ (Prospero et al., 2002; Engelstaedter et al., 2006). The greatest dust activity takes place near a system of salt lakes and dry lakes found in the lowlands of the Hamoun basin, which is surrounded by arid-rocky mountains to its north and west. This region is associated with drainage features and extensive alluvial deposits, exhibiting some similarities with the lowlands south of the Atlas Mountains in northwest Sahara (Kahn et al., 2009) and Lake Eyre in Australia (Baddock et al., 2009). The accumulation of recent and ancient sediments in such areas, often with salt, which enhances the weathering of sediments, makes them good sources of fine-grained mineral particles (Middleton, 1986) which might be transported potentially thousands of kilometers downwind (see Fig. 1). Intense dust storms originated from Hamoun are responsible for the dramatic increase in Aerosol Optical Depth (AOD) over the downwind areas. Alam et al. (2011a) reported that such an event occurred on 21 July 2007 when an intense dust plume originated from Hamoun and affected coastal Arabian Sea to such an extent that the AOD increased in Karachi to 1.36. The transport pathway of this dust plume was similar to the one shown in Fig. 1, indicating similarity in the source region and in regional and synoptic meteorological fields that favors the outbreak and advection of dust. Middleton (1986) used ground-based observations to explain the frequency and seasonality of 
dust storms in south-west Asia where the borders between Iran, Pakistan and Afghanistan were highlighted as an active dust source region with 81 dust storms that occurs annually. Furthermore, more than 30 dust storms were reported over Sistan.

\subsection{Dust loading measurements}

Dust activity is a function of several parameters, such as topography, rainfall, soil moisture, surface winds, regional meteorology, boundary layer height and convective activity. (Middleton and Goudie, 2001; Knippertz et al., 2009). The dust loading measured at the two stations that were located close to the Hamoun basin for several dust events during the period August 2009 to July 2010 are plotted in Fig. 8. In the same graph, meteorological data from the Zabol station that give information about the duration of dust events (for the examined days as well as in the preceding or succeeding days, i.e. about 2-3 days before the peak-day of the dust storm) and daily mean and maximum wind speeds, are also plotted.

The results of the average dust loading measured at eight heights at station $\mathrm{B}$ and at four heights at station A reveals considerable variation, ranging from $\sim 0.10$ to $\sim 2.5 \mathrm{kgm}^{-2}$. The average dust loadings for all the examined days were found to be $0.89 \mathrm{kgm}^{-2}$ (station A) and $0.93 \mathrm{kgm}^{-2}$ (station B), which do not exhibit a statistically significant difference. In general, the highest dust loading is observed for dust events occurring in summer, but intense dust storms can also take place in winter, since the Hamoun basin is located in an active dust source region throughout the year. The dust loading is highly correlated with the duration of the dust storms, as shown from their correlation, with the linear regressions being statistically significant at the $0.99 \%$ confidence level (Fig. 9). Apart from the strong linkage to the duration of dust storms, the dust loading at both stations also seems to have a dependence on the daily mean and maximum wind speeds (not presented). However, this dependence was found to be more obvious and statistically significant (at the $95 \%$ confidence level) at station $\mathrm{B}$, which is located closer to the dust source, whereas for station A the correlation was not found to be statistically significant. This finding emphasizes the strong effect of the wind speed on dust erosion and transportation, as well as on dust loading, at least for areas close to dust sources. However, the results show that the main factor that controls the dust loading at both stations is the duration of the dust storms, and secondly the wind speed. The role of the 
wind might have been more critical if measurements were taken at the sampler stations instead of using the meteorological data from Zabol. The total amount of dust loading represents large variation depending on intensity, duration and particle size distribution for each dust event. The analysis showed that the total dust loading for the 19 events of measurements at station $\mathrm{A}$ is $16.9 \mathrm{~kg} \mathrm{~m}^{-2}$ corresponding to $0.88 \mathrm{~kg} \mathrm{~m}^{-2}$ per event, whereas at station $B$ is these measurements yielded $15.8 \mathrm{~kg} \mathrm{~m}^{-2}$ (17 events), corresponding to $0.93 \mathrm{~kg} \mathrm{~m}^{-2}$. The larger dust loading at station B may be attributed to the smaller distance from the source region; however, this may be not so true since these values were obtained by experimental measurements with an unknown precision.

Fig. 10 illustrates the height variation in dust loading during the dust storms measured at station A (19 days, up to $4 \mathrm{~m}$ in height) and station B (17 days, up to $8 \mathrm{~m}$ in height). Contrasting height variations measured during intense dust storms occurred between the two stations, while similar variations correspond to moderate and low storm events. More specifically, the dust loading shows an increase (decrease) with height in station A (station B), revealing a difference in the dust transport mechanisms. This finding can be explained by considering the fact that station B is located closer to the Hamoun dust source region, meaning that uplift and newly transported dust concentration is higher near the surface. On the other hand, station A that is located about $20 \mathrm{~km}$ away the dust loading, presents larger values up to $3 \mathrm{~m}$ since the near ground dust particles have already been deposited near the source, and as the distance increases so does the dust-plume height. The diurnal variability of the dust loading at the two stations (not presented) showed increased mass concentrations during daytime that can be explained by enhanced convection and turbulent mixing in a deepened boundary layer. Furthermore, the local winds are stronger during daytime due to thermal convections.

\subsection{Dust grain-size distribution}

Supplementary to the dust loading measurements, the dust grain-size distribution was analyzed for selected samples at stations A and B by means of a Malvern Mastersizer 2000 analyzer. More specifically, the dust grain size was analyzed for 31 samples collected on 12 days at four height levels at station A and for 44 samples corresponding to eight days (eight 
heights) at station B. The average grain sizes for the selected dust events at stations A and B are summarized in Tables 1 and 2, respectively. The $\mathrm{d}(0.5)$ corresponds to the medium grain size (measured in $\mu \mathrm{m}$ ) of the particle distribution, while the $\mathrm{d}(0.9)$ implies that $90 \%$ of the grain size of particles is below this value. The percentages of $\mathrm{PM}_{2.5}$ and $\mathrm{PM}_{10}$ indicate the fraction of the particles that have diameters of below 2.5 and $10 \mu \mathrm{m}$, respectively.

The results in both Tables 1 and 2 show considerable variation in all grain-sized parameters, depending on the intensity of the dust storms as well as on other factors considering the soil materials. In general, dust storms that occurred during summer present larger grain sizes. As a consequence, a smaller fraction of particles is below 10 and $2.5 \mu \mathrm{m}$. However, more measurements are needed for evaluating these results. The whole spectrum of grain-size measurements at both stations is analyzed in Figs. 11a and b. These figures show box charts for each parameter that allows for a direct comparison between the two stations.

The analysis of the dusts grain size reveals large differences between the two stations, especially for the $\mathrm{d}(0.9)$. For this parameter, the mean, median as well as the distribution of the dust diameters are much higher at station B, exhibiting a mean value of $126.2 \pm 49.9 \mu \mathrm{m}$ against that of $58.7 \pm 18.0 \mu \mathrm{m}$ at station A. In general, the median grain size (d0.5) distributions of settled desert dust in Sistan is in the range of $\sim 10-118 \mu \mathrm{m}$ for both stations, with larger particle sizes and distribution of values at station B (Fig. 11a). For example, 50\% of the dusts are below $20.5 \pm 8.1 \mu \mathrm{m}$ at station A, while the same fraction is below $44.8 \pm 23.8$ $\mu \mathrm{m}$ at station B, implying considerable shift to larger dust particles at station B. This is also clearly observed when plotting the frequency distribution of particle size (Fig. 12). In Fig 12 the maximum of the mean distribution is around $30 \mu \mathrm{m}$ for station $\mathrm{A}$, which is increasing to $\sim 60-70 \mu \mathrm{m}$ for station B. Note also the dominance for higher frequencies of dust particles above $100 \mu \mathrm{m}$ at station $\mathrm{B}$, while the difference between the distributions are rather low for the small particles. This is particularly valid for particles $<2.5 \mu \mathrm{m}$, for which the results show fractions of $10.6 \pm 2.3 \%$ and $8.7 \pm 2.5 \%$ for stations $A$ and $B$, respectively (Fig. 11b) - much larger difference is shown for $\mathrm{PM}_{10}$, which is in the order of $10 \%$. Station $\mathrm{B}$, which is closer to Hamoun, exhibits slightly higher dust loading and significantly higher fraction of large particles than that observed at station A, which is $20 \mathrm{~km}$ from B and further from Hamoun. This is indicative of significant spatio-temporal variation in dust sediment loadings and grainsize distribution, which emphasizes the necessity for more systematic measurements, even at 
some new locations around the Hamoun basin in order to obtain an improve understanding of dust characteristics round Hamoun.

Finally, Fig. 13 provides the mean height variation in grain size parameters at station B. The profiles show a considerable decrease with height, mainly in $\mathrm{d}(0.9)$ and secondarily in $\mathrm{d}(0.5)$, indicating a shifting of size-distribution curves towards lower particle sizes. This suggests that the larger and heavier particles are found near the ground and that only the smaller particles are lifted to elevated heights meaning that they are more likely to be transported over large distances. As the particle size decreases, the height variability is gradually vanished, being neutral for $\mathrm{PM}_{2.5}$, while for $\mathrm{PM}_{10}$ the percentage fraction profile indicates a larger probability for occurrence at higher levels.

\section{5 $\mathrm{PM}_{10}$ measurements}

In order to provide a first in-situ analysis of the air quality and to compare the results with those obtained at Zahedan (located about $200 \mathrm{~km}$ south of Zabol) $\mathrm{PM}_{10}$ concentration measurements were obtained during the period September 2010 to July 2011 over Zabol, which is the largest city in the Sistan region (Rashki et al., 2011). This paper provides only some first results of the Zabol $\mathrm{PM}_{10}$ measurements which are still analyzed. For this purpose the hourly $\mathrm{PM}_{10}$ concentrations were daily averaged and the monthly and seasonal mean values are summarized in Table 3.

The results show extremely large $\mathrm{PM}_{10}$ concentrations at Zabol, although the instrumentation used for the $\mathrm{PM}_{10}$ monitoring is different between Zabol and Zahedan. Even the mean values are much higher than the most risky and dangerous maximum levels provided by the U.S. Environmental Protection Agency $\left(397 \mu \mathrm{gm}^{-3}\right)$. During each month, and especially during the period June to October, the area suffers from severe pollution since even the lower $\mathrm{PM}_{10}$ values are above $100 \mu \mathrm{g} \mathrm{m}^{-3}$, while the maximum ones are usually above $1000 \mu \mathrm{gm}^{-3}$. On the other hand, extreme $\mathrm{PM}_{10}$ measurements associated with severe dust events may also occur in other months, for example like December. Daily $\mathrm{PM}_{10}$ concentrations during major dust storms are about 10 to 20 times above the standard levels, and are much higher ( 1000 to $2000{\mu \mathrm{gm}^{-3}}^{3}$ than those measured for intense dust storms at Zahedan ( 400-600 $\left.\mu \mathrm{gm}^{-3}\right)$. Regarding the monthly mean $\mathrm{PM}_{10}$ concentrations, the results show extremely large values 


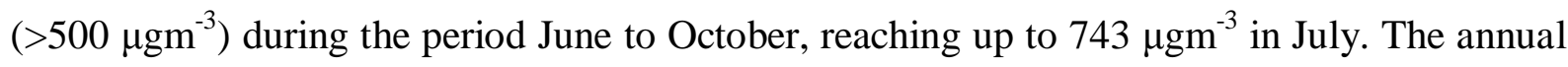
variation of $\mathrm{PM}_{10}$ in Zabol is similar to that recorded at Zahedan (Rashki et al., 2011), but with much higher values in at former site, in the order of $\sim 160-170 \mu \mathrm{gm}^{-3}$ in winter and spring and $\sim 510 \mu \mathrm{gm}^{-3}$ in summer. These large differences in $\mathrm{PM}_{10}$ concentrations between the two neighboring cities are attributed to severe dust storms that directly affect Zabol, which is located along the main pathway of intense dust plumes (see Fig. 1), while Zahedan is usually influenced by the wings of the dust storms originated from Hamoun. The " $U$ " shape is nearly similar for all the major dust events, so after influencing Zabol, the main dust plume is shifted to the east without directly affecting Zahedan (see Fig. 7).

\subsection{Air quality index}

In order to identify the impact of air pollution on human health, air pollution indices are commonly used, from which the AQI is the most well known index EPA, 1999; Mohan and Kandya, 2007; Larissi et al., 2010b). The AQI is divided into six categories, varying from 0 to 500, with different health impacts as listed in Table 4. The AQI for Zabol was calculated for the period September 2010 to July 2011 using the same technique as for Zahedan in a previous study by Rashki et al. (2011). This will make comparisons of air quality between the two cities possible.

Assessment of air quality in Zabol shows that 193 days out of $316(61 \%)$ exhibit air pollution levels of above the air quality standards $\left(>155 \mu \mathrm{gm}^{-3}\right)$, a fraction that is much higher than that (21.5\%) reported for Zahedan. The most exciting finding is the 95 days $(30.1 \%)$ that are characterized as hazardous (Table 4), which in combination with the human health adverse effects, make it clear that environmental conditions in the Sistan region are rather poor for human well-being. On the other hand, only $6.6 \%$ of the days are associated with low pollution levels when the air quality is considered satisfactory and air pollution poses little or no risk. Several studies have shown that ambient air pollution is highly correlated with respiratory morbility, mainly amongst children (Bartzokas et al., 2004; Nastos et al., 2010; Samoli et al., 2011). The results gathered from hospitals in the Sistan region showed that during dust storms respiratory patients increased significantly, especially those affected by chronic obstructive pulmonary disease and asthma. The percentage of these diseases increases in summer (June 
and July) because of more severe dust storms and a further deterioration of air quality (Miri et al., 2007). Except of the dust storms, re-suspended dust within the urban environment is a strong source of $\mathrm{PM}_{10}$ concentrations, while urban-anthropogenic and industrial activities are considered to have a much lower effect on the air pollution over Zabol.

\section{Conclusions}

This paper provides analysis of the dust sediment loading and grain size distribution in the Sistan region, southeast Iran, based on first time measurements conducted at two locations that are located close to the Hamoun basin. Hamoun is considered to be one of the most active dust source regions in South west Asia. Meteorological data of the nearby Zabol station showed a dramatic increase in dust storm frequency and intensity, as well as a significant reduction in visibility over the last decade, most probably because of a drought period in the 1990s. The drainage of the Hamoun wetlands, in association with the intense Levar winds in summer, is the main factor responsible for the frequent and massive dust storms over the region. The OMI-AI satellite values highlighted Hamoun as an intense dust source region causing a dramatic increase in $\mathrm{PM}_{10}$ concentrations and a deterioration of air quality $(61 \%$ of the days were considered unhealthy for sensitive people and $31 \%$ as hazardous) in Zabol city. Dust loading from the Hamoun basin appears to have a significant contributing influence on the development of extreme dust storms, especially during the summer days. This influence firstly seems to depend on the intensity and duration of dust storms, and secondarily, on the distance from the source region, the wind speed and altitude. The grain-size distribution of the dust loading was strongly influenced by the distance from the dust source, since grain sizes shifted to larger values towards station B that is closer to the Hamoun basin. Furthermore, the particle size distribution exhibited a shift towards lower values as the altitude increases, with this feature to be more obvious amongst larger size particles, while the frequency of particles below $2.5 \mu \mathrm{m}$ seemed not to be affected by altitude. In general, the analysis revealed significant spatio-temporal variability of regional dust loading and characteristics. This finding necessitate more systematic observations at as many locations as possible around the Hamoun basin in order to improve the understanding of force dynamics, transport mechanisms as well as to quantify the dust amounts emitted from the Hamoun basin. 


\section{Acknowledgements}

The authors are thankful to the persons, scientists and technical staff at the Natural and Agricultural research centre of Sistan that established and maintain the two stations in the Sistan region, as well as for providing data of the Zabol meteorological station via the Iran Meteorological Organization website. Analyses and visualizations used in this study were produced with the Giovanni online data system, developed and maintained by the NASA GES DISC. The authors also acknowledge the OMI mission scientists and associated NASA personnel for generating the data used in this research.

\section{References}

Adamopoulos, A.D., Kambezidis, H.D., Kaskaoutis, D.G., Giavis, G., 2007. A study of particle size in the atmosphere of Athens, Greece retrieved from solar spectral measurements. Atmos. Res. 86, 194-206.

Alam, K., Trautmann, T., Blaschke, T., 2011a. Aerosol optical properties and radiative forcing over mega-city Karachi. Atmos. Res., 101, 773-782.

Alam, K., Qureshi, S., Blaschke, T., 2011b. Monitoring Spatio-temporal aerosol patterns over Pakistan based on MODIS, TOMS and MISR satellite data and a HYSPLIT model. Atmospheric Environment 45, 4641-4651.

Baddock, M.C., Bullard, J.E., Bryant, R.G., 2009. Dust source identification using MODIS: A comparison of techniques applied to the Lake Eyre Basin, Australia. Rem. Sens. Environ. $113,1511-1528$.

Bartzokas, A., Kassomenos, P., Petrakis, M., Celessides, C., 2004. The effect of meteorological and pollution parameters on the frequency of hospital admissions for cardiovascular and respiratory problems in Athens. Indoor and Built Environ. 13, 271275.

Bayat, A., Masoumi, A., Khalesifard, H.R., 2010. Retrieval of atmospheric optical parameters from ground-based sun-photometer measurements for Zanjan, Iran. Atmos. Measur. Techn. Discuss. 3, 2633-2649.

Claquin, T., Schulz, M., Balkanski, Y., Boucher, O., 1998. Uncertainties in assessing radiative forcing by mineral dust. TellusB 50, 491-505.

De Graaf, M., Stammes, P., Torres, O., Koelemeijer, R.B.A., 2005. Absorbing Aerosol Index: Sensitivity Analysis, application to GOME and comparison with TOMS. J. Geophys. Res. 110, D01201, doi: 10.1029/2004JD005178. 
Dey, S., and di Girolamo, L., 2010. A climatology of aerosol optical and microphysical properties over the Indian subcontinent from 9 years (2000-2008) of Multiangle Imaging Spectroradiometer (MISR) data. J. Geophys. Res., 115, D15204, doi:10.1029/2009JD013395.

Dockery, D., Pope, A., 1996. Epidemiology of acute health effects: summary of time-series studies. In: Particles in Our Air: Concentrations and Health Effects (Wilson R, SpenglerJD, eds). Harvard University Press, Cambridge, MA, pp.123-147.

Dunion, J., Velden, C., 2004. The impact of the Saharan air layer on Atlantic tropical cyclone activity. Bull. Amer. Meteor. Soc. 85, 353-365.

Ekhtesasi, M.R., Daneshvar, M.R., Abolghasemi, M., Feiznia, S., and Saremi Naeini, M.A. Measurement and Mapping of Aeolian Sand Flowthrough Sediment Trap Method (Case Study: Yazd-Ardakan Plain), Journal of the Iranian Natural Res., Vol. 59, No. 4, 2007, pp. 773-781

El-Askary, H., Gautam, R., Singh, R.P., Kafatos, M., 2006. Dust storms detection over the Indo-Gangetic basin using multi sensor data. Adv. Space Res. 37, 728-733.

Engelstaedter, S., Tegen, I., Washington, R., 2006. North African dust emissions and transport. Earth Science Reviews 79, 73-100.

Environmental Protection Agency (EPA), 1999. Guideline for reporting the daily air qualityair quality index (AQI). EPA-1999-454/R-99-010.

Gautam, R., Liu, Z., Singh, R. P., Hsu, N.C., 2009. Two contrasting dust-dominant periods over India observed from MODIS and CALIPSO data. Geophys. Res. Lett., 36, L06813, doi:10.1029/2008GL036967.

Goudie, A.S., 1983. Dust storms in space and time. Progress in Physical Geography 7, 502530.

Goudie, A.S., Middleton, N.J., 1992. The changing frequency of dust storms through time. Climate Change 20, 197-223.

Goudie, A.S., Middleton, N.J., 2000. Dust storms in south west Asia. Acta Universitatis Carolinae, Supplement 73-83.

Goudie, A. S., and Middleton.N.J., 2001. Saharan dust storms: nature and consequences. Earth-Science Reviews 56: 179-204.

Goudie, A.S., Middleton, N.J., 2006. Desert dust in the global system, Springer. 2006.

Hegde, P., Pant, P., Naja, M., Dumka, U.C., Sagar, R., 2007. South Asian dust episode in June 2006: Aerosol observations in the central Himalayas. Geophys. Res. Lett., 34, L23802, doi:10.1029/2007GL030692.

Hossenzadeh, S.R., 1997. One hundred and twenty days winds of Sistan. Iran J. Res. Geography 46,103-127. 
Hsu, N.C., Herman, J.R., Torres, O., Holben, B.N., Tanre, D., Eck., T.F., Smirnov, A., Chatenet, B., Lavenu, F., 1999. Comparisons of the TOMS aerosol index with sun photometer aerosol optical thickness: results and applications. J. Geophys. Res. 104, 6269-6279.

IPCC, (Intergovernmental Panel on Climate Change), 2001. Climate Change 2001: The Scientific Basis. In Contribution of Working Group I to the Third Assessment Report of the Intergovernmental Panel on Climate. J.T. Houghton et al.; Eds, Cambridge Univ. Press, New York, USA.

IPCC, 2007. Climate Change 2007: Synthesis Report. Contribution of Working Groups I, II and III to the Fourth Assessment Report of the Intergovernmental Panel on Climate Change. In: Core Writing Team, Pachauri, R.K., Reisinger, A. (Eds.), Geneva, Switzerland, p. 104.

Janssen, W. and Tetzlaff, G., 1991. Entwicklung und Eichung einer registrierenden Suspensionsfalle. Zeitschrift für Kulturtechnik und Landesentwicklung 32, 167-180.

Kahn, R., Petzold, A., Wendisch, M., Bierwirth, E., Dinter, T., Esselborn, M., Fiebig, M., Heese, B., Knippertz, P., Muller, D., Schladitz, A., Von Hoyningen-Huene, W., 2009. Desert dust aerosol air mass mapping in the western Sahara, using particle properties derived from space-based multi-angle imaging. TellusB, 61, 239-251.

Kandler, K., Schütz, L., Deutscher, C., Ebert, M., Hofmann, H., Jäckel, S., Jaenicke, R., Knippertz, P., Lieke, K., Massling, A., Petzold, A., Schladitz, A., Weinzierl, B., Wiedensohler, A., Zorn, S., Weinbruch, S. 2009. Size distribution, mass concentration, chemical and mineralogical composition and derived optical parameters of the boundary layer aerosol at Tinfou, Morocco, during SAMUM 2006. TellusB, 61, 32-50.

Kaskaoutis, D.G., Kalapureddy, M.C.R., Krishna Moorthy, K., Devara, P.C.S., Nastos, P.T., Kosmopoulos, P.G., Kambezidis, H.D., 2010b. Heterogeneity in pre-monsoon aerosol types over the Arabian Sea deduced from shipboard measurements of spectral AODs. Atmos. Chem. Phys. 10, 4893-4908.

Kaskaoutis, D.G., Kambezidis, H.D., Badarinath, K.V.S., Kumar Kharol, S., 2010a. Dust storm identification via satellite remote sensing. In: Dust Storms: Elemental Composition, Causes and Environmental Impacts. Eds: Siniša Brstilo and Quentin Madunic, Nova Science Publishers, ISBN-13: 978-1608769063, pp. 1-59.

Kaskaoutis, D.G., Nastos, P.T., Kosmopoulos, P.G., Kambezidis, H.D., Kumar Kharol, S., Badarinath, K.V.S., 2010c. The Aura-OMI Aerosol Index distribution over Greece. Atmos. Res. 98, 28-39.

Kim, D., Chin, M., Yu, H., Eck, T.F., Sinyuk, A., Smirnov, A., Holben, B.N., 2011. Dust optical properties over North Africa and Arabian Peninsula derived from the AERONET dataset. Atmos. Chem. Phys. Discuss. 11, 20181-20201. 
Knippertz, P., Ansmann, A., Althausen, D., et al., 2009. Dust mobilization and transport in the northern Sahara during SAMUM 2006 - A meteorological overview. Tellus B 61, 12-31.

Larissi, I.K., Antoniou, A., Nastos, P.T., Paliatsos, A.G., 2010a. The role of wind in the configuration of the ambient air quality in Athens, Greece. Fres. Environ. Bull. 19, 19891996.

Larissi, I.K., Koukouletsos, K.V., Moustris, K.P., Antoniou, A., Paliatsos, A.G., 2010b. PM10 concentration levels in the greater Athens area, Greece. Fresen Environ Bull. 19:226-231

Maghrabi, A., Alharbi, B., Tapper, N., 2011. Impact of the March 2009 dust event in Saudi Arabia on aerosol optical properties, meteorological parameters, sky temperature and emissivity. Atmos. Environ. 45, 2164-2173.

Mahowald, N., Baker, A., Bergametti, G., Brooks, N., Duce, R., Jickells, T., Kubilay, N., Prospero, J., Tegen, I., 2005. Atmospheric global dust cycle and iron inputs to the ocean. Global Biogeoch. Cycles 19, GB4025, doi: 10.1029/2004GB002402.

Middleton, N. J., 1986. Dust storms in the Middle East. J. Arid Environ. 10, 83-96.

Middleton, N.J., Goudie, A.S., 2001. Saharan dust: sources and trajectories. Trans. Inst. Br. Geogr. 26, 165-181.

Miri, A., Ahmadi, H., Ghanbari, A., Moghaddamnia, A., 2007. Dust Storms Impacts on Air Pollution and Public Health under Hot and Dry Climate. Int. J. Energy and Environ. 2, 1.

Mishchenko, M.I., Geogdzhayev, I.V., 2007. Satellite remote sensing reveals regional tropospheric aerosol trends. Optics Express 15, 7423-7438

Moghaddamnia, A., Ghafari, M.B., Piri, J., Amin.S., Han. D., 2009. Evaporation estimation using artificial neural networks and adaptive neuro-fuzzy inference system techniques. Adv. Water Resources 32, 88-97.

Mohan, M., Kandya, A., 2007. An analysis of the annual and seasonal trends of Air Quality Index of Delhi. Environ. Monit. Assess. 131, 267-277.

Nastos, P.T., Paliatsos, A.G., Anthracopoulos, M.B., Roma, E.S., Priftis, K.N., 2010. Outdoor particulate matter and childhood asthma admissions in Athens, Greece: A time-series study. Environmental Health: A Global Access Science Source 9, art. no. 45, doi:10.1186/1476-069X-9-45.

Patadia, F., Yang, E.-S., Christopher, S.A., 2009. Does dust change the clear sky top of atmosphere shortwave flux over high surface reflectance regions? Geophys. Res. Lett., 36, L15825, doi:10.1029/2009GL039092.

Prasad, A.K., Singh, S., Chauhan, S.S., Srivastava, M.K., Singh, R.P., Singh, R., 2007. Aerosol radiative forcing over the Indo-Gangetic Plains during major dust storms. Atmos. Environ. 41, 6289-6301.

Prasad, A.K., Yang, K.-H.S., El-Askary, H.M., Kafatos, M., 2009. Melting of major glaciers in the western Himalayas: evidence of climatic changes from long term MSU derived tropospheric temperature trend (1979-2008). Ann. Geophys. 27, 4505-4519. 
Prospero, J.M., Ginoux, P., Torres, O., Nicholson, S.E., Gill, T.E., 2002. Environmental characterization of global sources of atmospheric soil dust identified with the Nimbus 7 total ozone mapping spectrometer absorbing aerosol product. Reviews of Geophys. 40, $2-31$.

Rashki, A., Rautenbach, C.J.deW., Eriksson, P.G., Kaskaoutis, D.G., Gupta, P., 2011. Temporal changes of particulate concentration in the ambient air over the city of Zahedan, Iran. Air Quality, Atmosphere \& Health. DOI: 10.1007/s11869-011-0152-5

Samoli, E., Kougea, E., Kassomenos, P., Analitis, A., Katsouyanni, K., 2011. Does the presence of desert dust modify the effect of PM10 on mortality in Athens, Greece? Sci. Total Environ. 409, 2049-2054.

Satheesh, S.K., Vinoj, V., Moorthy, K.K., 2010. Assessment of aerosol radiative impact over oceanic regions adjacent to Indian subcontinent using Multisatellite analysis. Adv. in Meteorol. ID 139186, doi:10.1155/2010/139186.

Singh, R.P., Prasad, A.K., Kayetha, V.K., Kafatos, M., 2008. Enhancement of oceanic parameters associated with dust storms using satellite data. J. Geophys. Res., 113, C11008, doi:10.1029/2008JC004815.

Smirnov, A., Holben, B.N., Dubovic, O., O’Neill, N.T., Eck, T.F., Westphal, D.L., Goroth, A.K., Pietras, C., Slutsker, I., 2002. Atmospheric aerosol optical properties in the Persian Gulf. J. Atmos. Sci. 59, 620-634.

Tegen, I., Fung, I., 1994. Modeling of mineral dust in the atmosphere: sources, transport, and optical thickness. J. Geophys. Res. 99, 22897-22914.

Tegen, I., Lacis, A.A., Fung, I., 1996. The influence on climate forcing of mineral aerosols from disturbed soils. Nature, 380, 419-422.

Triantafyllou, A.G., Evagelopoulos, V., Zoras, S., 2006. Design of a web-based information system for ambient environmental data. Journal of Environmental Management, 80, 230-236.

USEPA, 2006.Guideline for Reporting of Daily Air Quality: Air Quality Index, Environmental Protection Agency, Washington, DC. P. 17.

Washington, R., Todd, M.C., Middleton, N.J., Goudie, A.S., 2003. Dust-storm source areas determined by the total ozone monitoring spectrometer and surface observations. Annals of the Association of American Geographers 93, 297-313. 
Table 1: Variation in average grain size during different dust storms at station A.

\begin{tabular}{l|cccc}
\hline Date & $\mathrm{d}(0.5)$ & $\mathrm{d}(0 . \mathrm{C}$ & $\mathrm{PM} 2.5(\%$ & $\mathrm{PM} 10(\%$ \\
\hline $08 / 19 / 2009$ & 24.1 & 61.0 & 8 & 24 \\
$08 / 25 / 2009$ & 19.9 & 56.0 & 11.0 & 30.0 \\
$09 / 05 / 2009$ & 26.1 & 64.5 & 9.5 & 24.0 \\
$09 / 09 / 2009$ & 28.2 & 73.8 & 10.5 & 26.0 \\
$09 / 16 / 2009$ & 14.3 & 46.9 & 8 & 38 \\
$10 / 09 / 2009$ & 23.8 & 63.4 & 10.3 & 27.5 \\
$11 / 15 / 2009$ & 10.1 & 36.2 & 15.3 & 50.7 \\
$01 / 07 / 2010$ & 14.8 & 56.0 & 11.7 & 40.8 \\
$01 / 09 / 2010$ & 12.6 & 42.6 & 11.0 & 51.3 \\
$01 / 23 / 2010$ & 13.5 & 45.0 & 11.0 & 41.5 \\
$07 / 08 / 2010$ & 29.9 & 77.2 & 9.5 & 26.0 \\
$08 / 23 / 2010$ & 31.5 & 80.6 & 8.0 & 20.8 \\
\hline
\end{tabular}

Table 2: Same as in Table 1, but for station B.

\begin{tabular}{c|llll}
\hline Date & $\boldsymbol{d}(\mathbf{0 . 5})$ & $\boldsymbol{d}(\mathbf{0 . 9})$ & $\boldsymbol{P M 2 . 5}(\%)$ & PM10 (\%) \\
& & & & \\
\hline $09 / 05 / 2009$ & 63 & 163 & 7 & 18 \\
$09 / 09 / 2009$ & 55 & 149 & 7 & 17 \\
$09 / 16 / 2009$ & 37 & 115 & 9 & 23 \\
$10 / 09 / 2009$ & 61 & 159 & 7 & 19 \\
$10 / 16 / 2009$ & 36 & 102 & 8 & 24 \\
$11 / 15 / 2009$ & 32 & 96 & 9 & 25 \\
$01 / 07 / 2010$ & 14 & 54 & 13 & 41 \\
$07 / 08 / 2010$ & 49 & 147 & 9 & 22 \\
\hline
\end{tabular}


Table 3: Monthly mean, daily maximum and daily minimum $\mathrm{PM}_{10}$ concentrations in Zabol during the period September 2010 to July 2011.

\begin{tabular}{|c|c|c|c|}
\hline & Monthly Mean & Daily minimum & Daily maximum \\
\hline Season & $\begin{array}{c}\text { PM10 } \\
(\mu \mathrm{gm}-3)\end{array}$ & $\begin{array}{c}\text { PM10 } \\
(\mu \mathrm{gm}-3)\end{array}$ & $\begin{array}{c}\text { PM10 } \\
(\mu \mathrm{gm}-3)\end{array}$ \\
\hline January & 196 & 29 & 597 \\
\hline February & 147 & 13 & 787 \\
\hline March & 262 & 21 & 2698 \\
\hline April & 224 & 97 & 515 \\
\hline May & 322 & 71 & 1276 \\
\hline June & 622 & 100 & 1875 \\
\hline July & 743 & 102 & 1902 \\
\hline September & 720 & 88 & 2045 \\
\hline October & 531 & 100 & 2339 \\
\hline November & 200 & 66 & 737 \\
\hline December & 476 & 84 & 3094 \\
\hline Winter & 273 & 13 & 3094 \\
\hline Spring & 289 & 21 & 2698 \\
\hline Summer & 683 & 102 & 1902 \\
\hline Autumn & 484 & 66 & 2339 \\
\hline
\end{tabular}

Table 4: Health quality as determined by the Air Quality Index (AQI), $\mathrm{PM}_{10}$ and number of days with severe pollution in Zabol during the period September 2010 to July 2011.

\begin{tabular}{|l|l|l|l|l|}
\hline \multicolumn{1}{|c|}{ Health Quality } & \multicolumn{1}{|c|}{ AQI } & \multicolumn{1}{|c|}{ PM $_{\mathbf{1 0}}\left(\boldsymbol{\mu g} \mathbf{~ m}^{-3}\right)$} & Days & \multicolumn{1}{c|}{$(\%)$} \\
\hline Good & & & & \\
Moderate & $0-50$ & $0-54$ & 21 & 6.6 \\
Unhealthy for sensitive people & $51-100$ & $55-154$ & 102 & 32.3 \\
Unhealthy & $101-150$ & $155-254$ & 58 & 18.4 \\
Very unhealthy & $151-200$ & $254-354$ & 31 & 9.8 \\
Hazardous & $201-300$ & $355-424$ & 9 & 2.8 \\
\hline
\end{tabular}




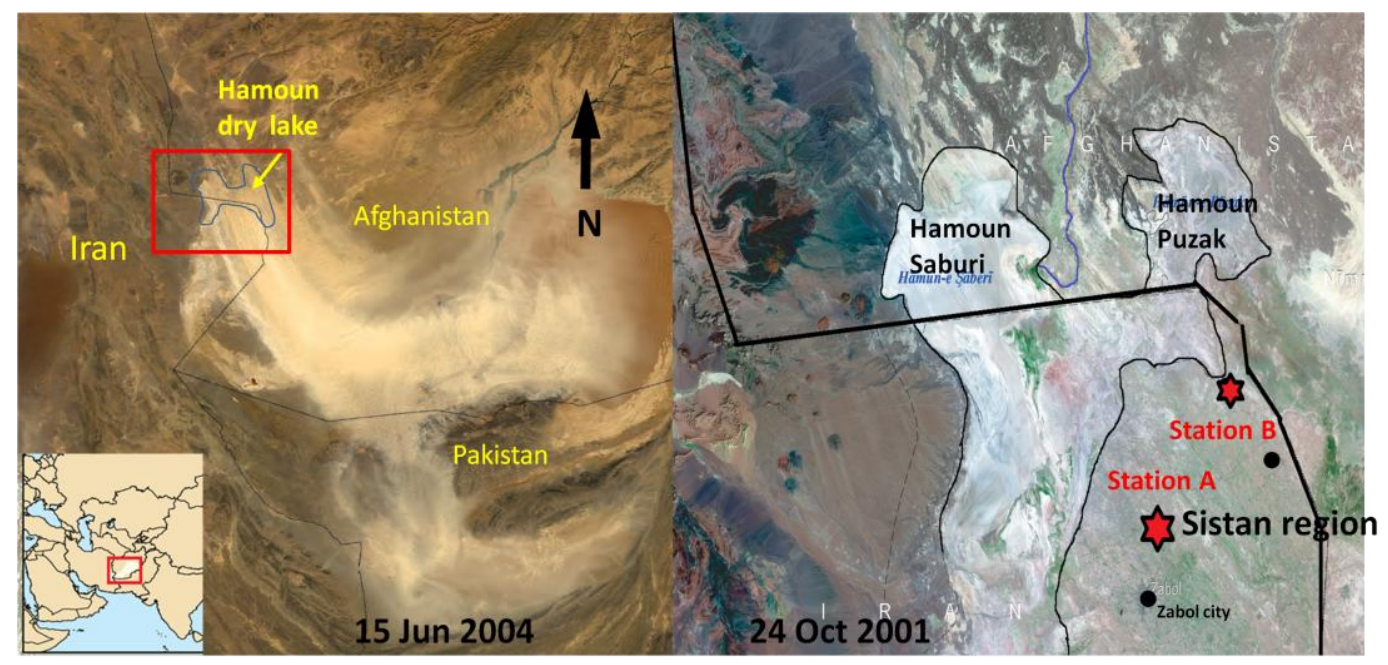

Figure 1. Map of the Sistan region in southeastern Iran with the locations of the dust loading measurements (station A and B) and the Zabol city (location of the $\mathrm{PM}_{10}$ observations). The left image shows an intense dust storm that originated from the Hamoun basin on 15 June 2004 (Terra MODIS satellite image), while the right image zooms in on the Hamoun wetlands on 24 October 2004. [source:http://earthobservatory.nasa.gov/NaturalHazards/view.php?id=42242] 

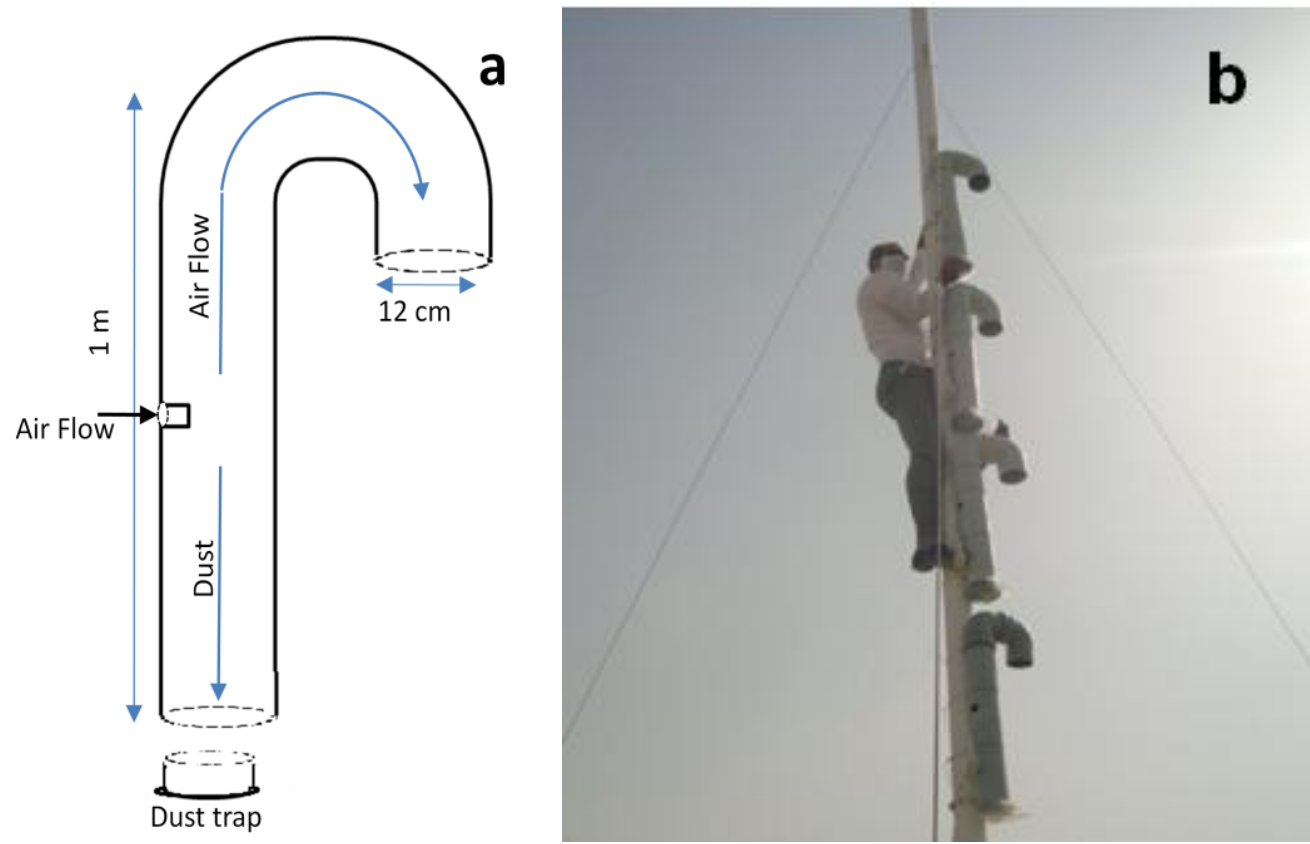

Figure 2. Schematic diagram of the dust sampler system (a) and photo of the $8 \mathrm{~m}$ dust monitoring tower $(b)$.

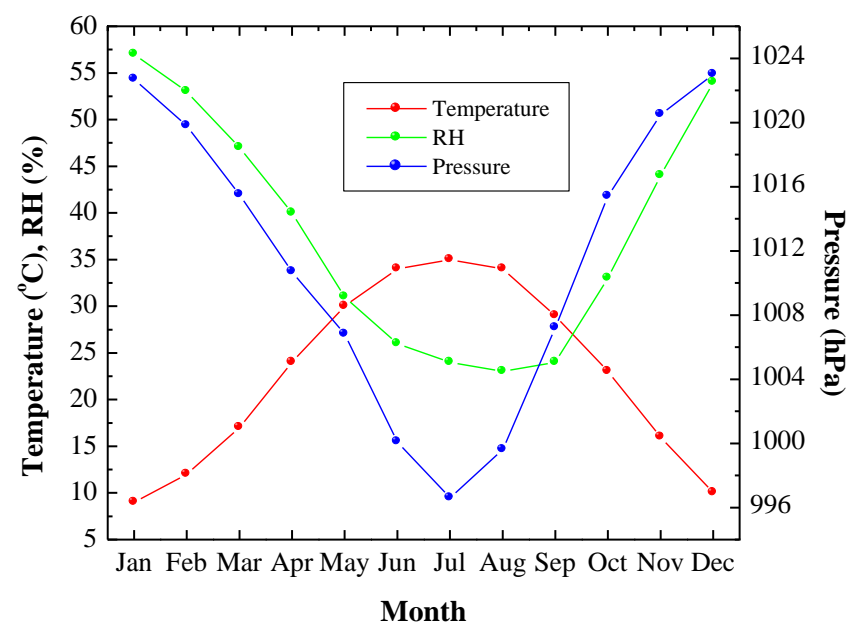

Figure 3. Monthly mean variation of air Temperature (T), Relative Humidity (RH) and atmospheric Pressure (P) in Zabol during the period 1963 to 2010. 


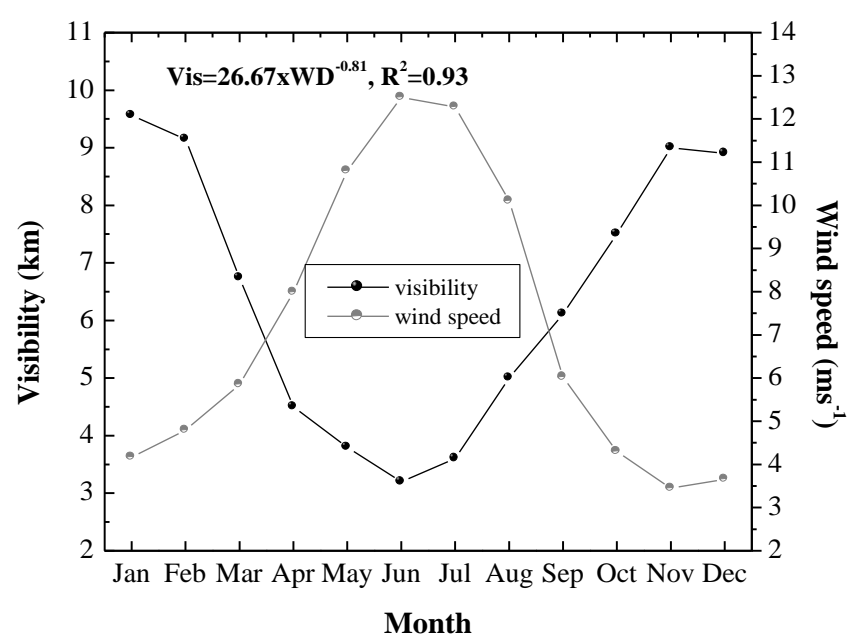

Figure 4. Monthly mean variation of the visibility $(\mathrm{km})$ and wind speed $\left(\mathrm{ms}^{-1}\right)$ in Zabol during the period 1963 to2009.
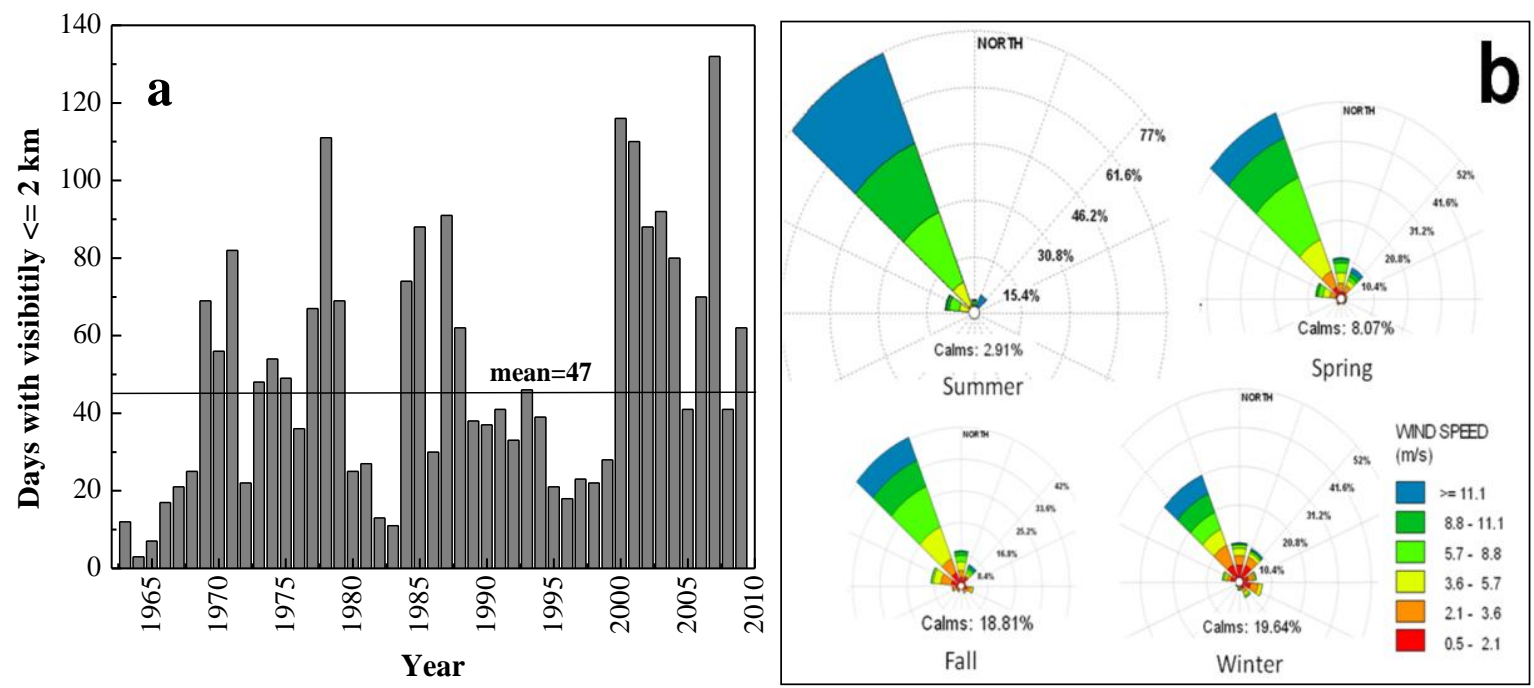

Figure 5. Annual variation of days with visibility $<=2 \mathrm{~km}$ (a) and wind rose of seasonal wind speed and direction frequencies in Zabol during the period 1963 to 2009. 


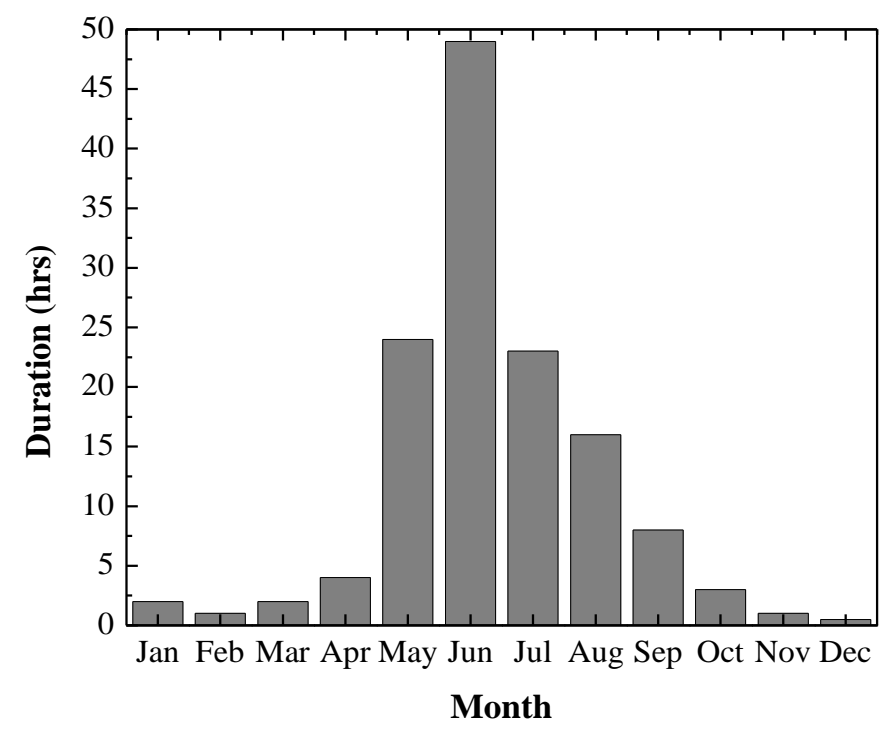

Figure 6. Annual variation of the average duration of dust storms (in hours) in Zabol during the period 1999 to 2009. 


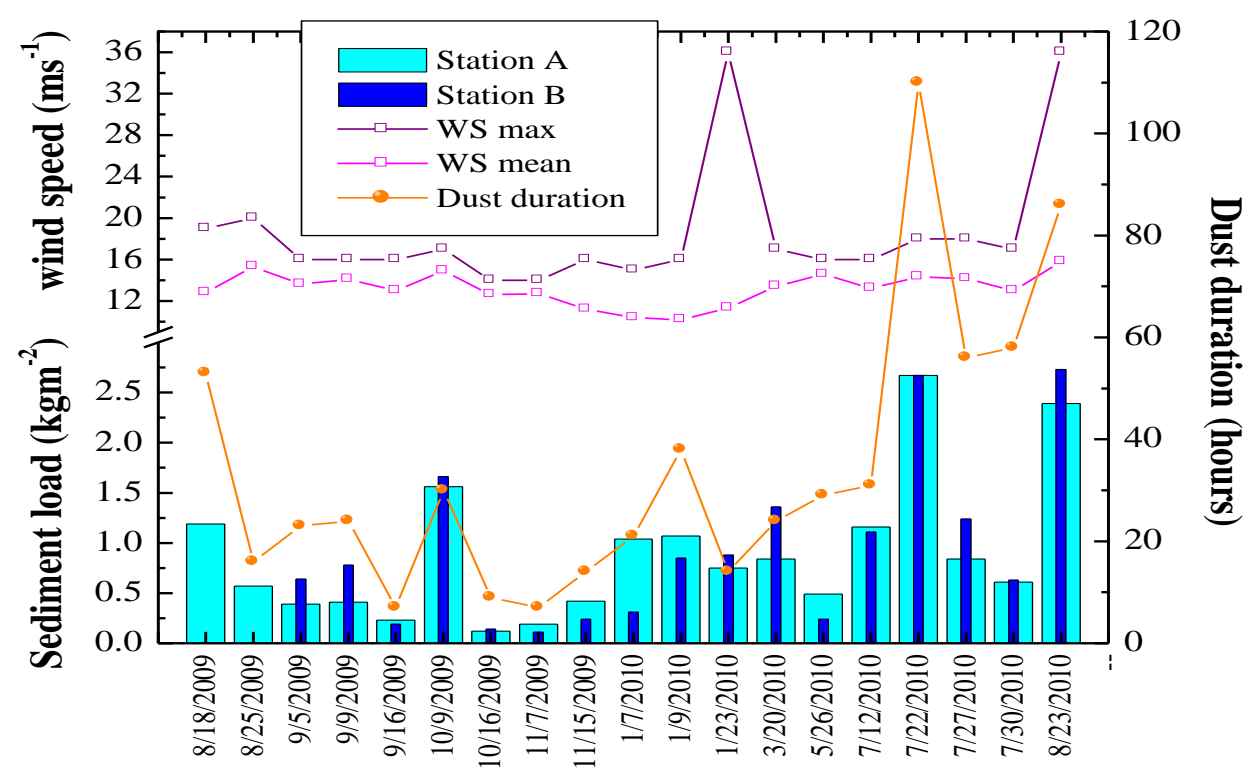

Date

Figure 8. Average dust loading $\left(\mathrm{kgm}^{-2}\right)$ during various dust events in the Sistan region as measured at the $4 \mathrm{~m}$ (station A) and $8 \mathrm{~m}$ (station B) monitoring towers. The duration of dust events (hours), as well as the mean and maximum wind speeds on the dusty days were obtained from the Zabol meteorological station.

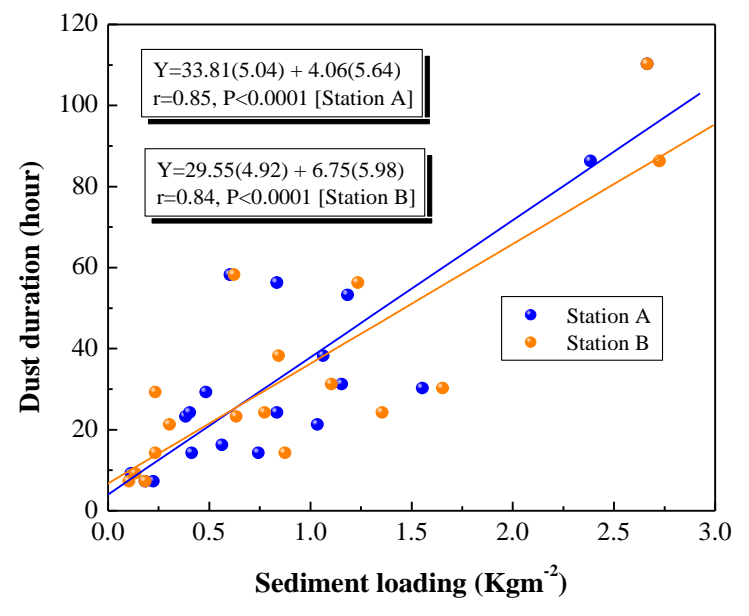

Figure 9. Correlation between dust loading measurements and duration of dust storm events for 19 days at station A and 17 days at station B. 

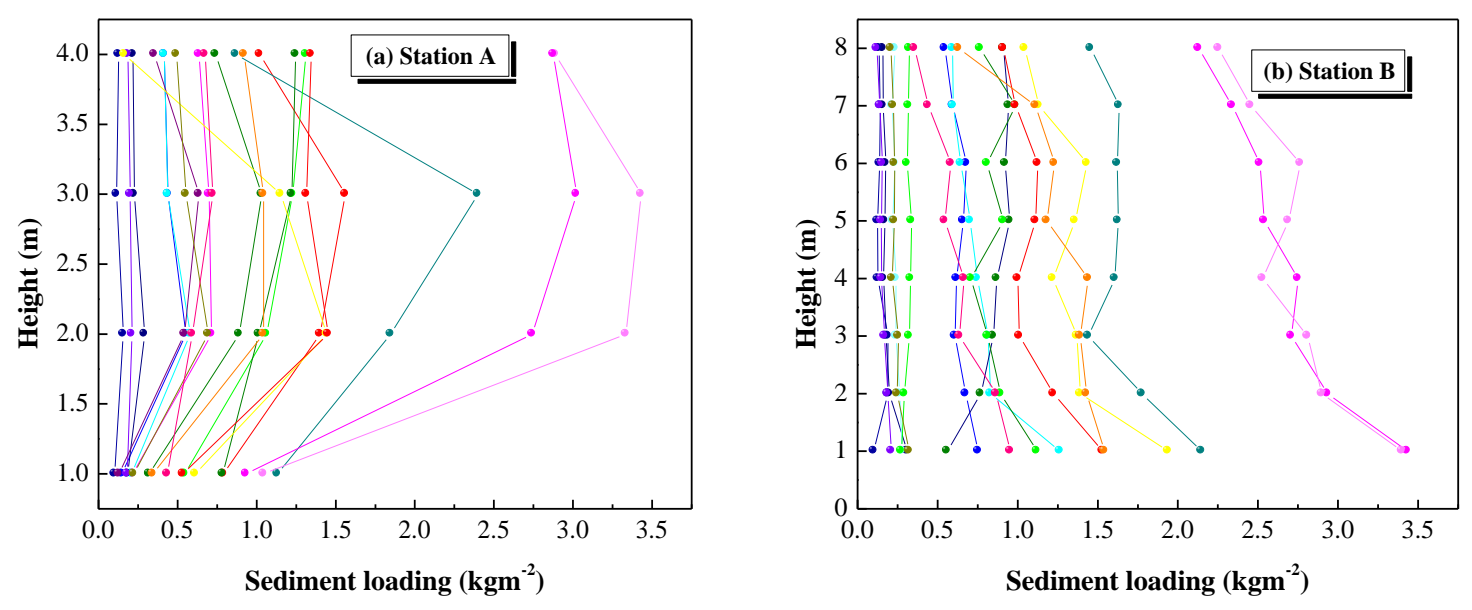

Figure 10. Height variation of the dust loading at station A (a) and at station B (b) for several dust storm days. Green colors are loadings for winter, yellow for spring, red for summer and blue for autumn.

(a)

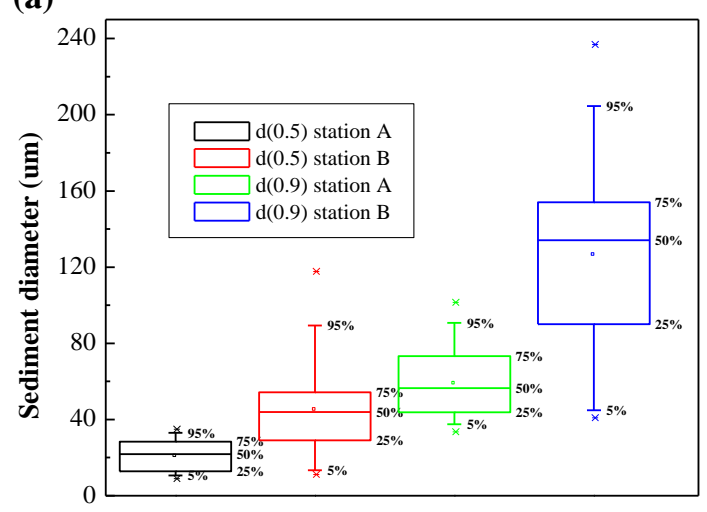

(b)

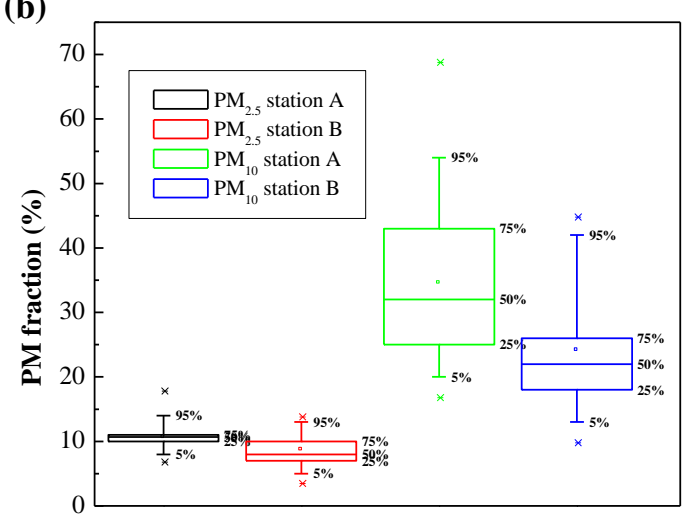

Figure 11. Chart boxes for the dust diameters (a) corresponding to $d(0.5)$ and $d(0.9)$ grain sizes and for the percentage (\%) fraction for dust concentrations lower than 2.5 and $10 \mu \mathrm{m}$ (b) at both stations A and B. 


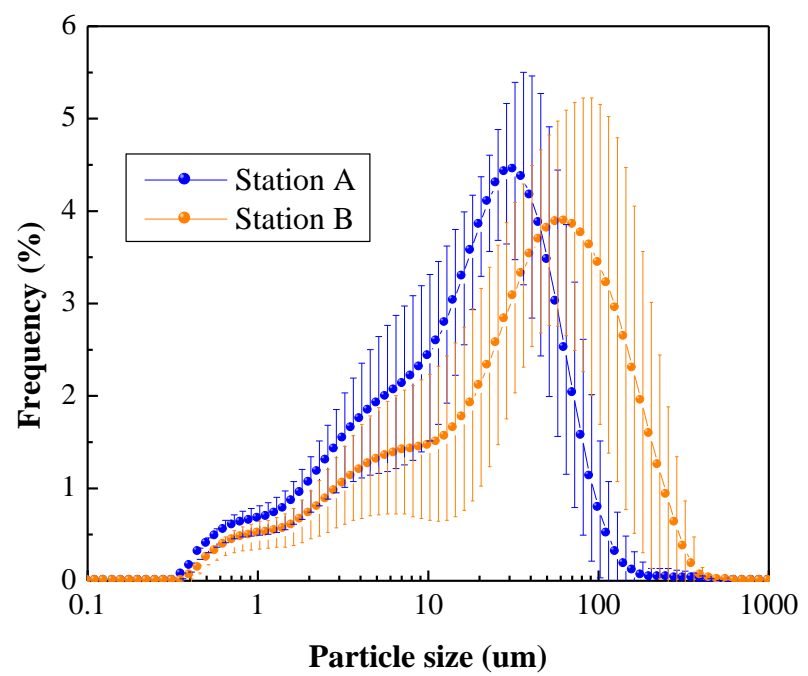

Figure 12. Average and standard deviation of the particle size distribution at stations $A$ and B.

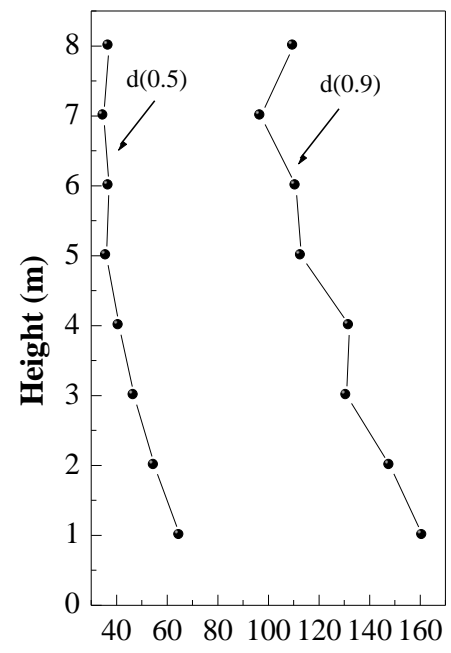

Sediment diameter (um)

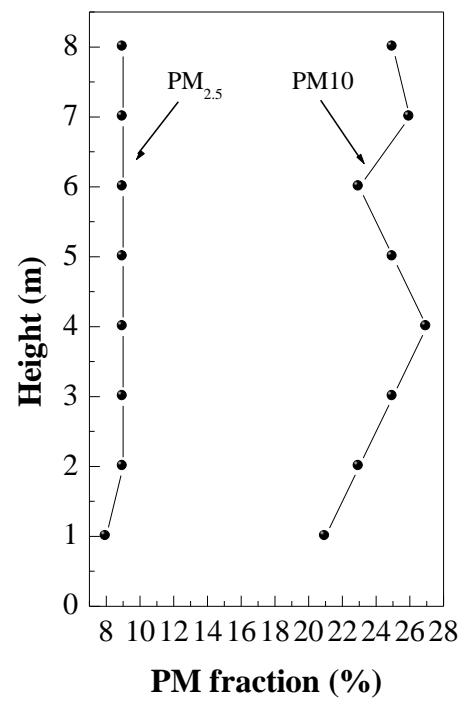

Figure 13. Average height variation of the grain size measured over eight days at station $B$ for $\mathrm{d}(0.9)$ and (d0.5) (left panel) and $\mathrm{PM}_{2.5}$ and $\mathrm{PM}_{10}$ (right panel). 